\title{
La inseguridad: el regulador de la economía mundial
}

FRANCISCO JAVIER IBISATE

\section{Un gran tablero de ajedrez}

No es exagerado decir que nunca el mundo ha estado tan conectado por los mercados, los flujos de capitales, las telecomunicaciones, y nunca el mundo se ha sentido tan desunido por el resurgimiento del nacionalismo, la xenofobia, el recelo de las civilizaciones, la inseguridad, y por el poderoso unilateralismo en importantes decisiones políticas. Nuestro mundo parece ser un gran tablero de ajedrez, donde las partidas se juegan, a la vez, desde los cuatro costados. Hay un jugador presente, pero escondido, que amenaza con el jaque mate al rey, a la reina y a las 'torres'. Frente a frente el rey y la reina, que, asustados por esta amenaza, llegan a pactar un acuerdo para interceptar el jaque mate del jugador invisible. En el cuarto costado quisieran jugar otros países, que ven consternados cómo los grandes ajedrecistas les comen los pocos peones con que ellos pueden participar en la economía mundial. A los grandes campeones les preocupa más la primera partida y parecen decir a los pequeños: sobre lo vuestro os escucharemos hablar mañana.

En víspera de los foros económico y social de Davos-Nueva York y Porto Alegre, el presidente George W. Bush presentó ante el Congreso "el estado de la Unión". Este discurso sacudió la atención mundial: "América está en guerra, América está en recesión, América nun-

Lo inseguridod: el regulodor de lo economio mundial 
ca ha estado tan fuerte" (Le Monde, 30-01-02). Con este discurso Bush relanzaba la guerra contra el terrorismo, identificando a tres países como el "eje del mal": Irak, Irán y Corea del Norte. Los desacuerdos se hacen presentes en el mismo foro de Nueva York, porque los problemas de una economía frágil perdían atención, mientras que la lucha contra el terrorismo se convertía en el problema número uno del gobierno de Estados Unidos. En el foro de Porto Alegre se da el toque de alarma por las consecuencias mundiales de este unilateralismo: "El 11 de septiembre ha producido un cambio radical. Luego de los atentados terroristas, que nosotros condenamos, como condenamos todos los ataques contra civiles en cualquier parte del mundo, el gobierno de Estados Unidos y sus aliados han lanzado una operación militar masiva contra el terrorismo. La guerra terrorista contra Afganistán tiende a extenderse sobre otros frentes... Después de los atentados, los temas sociales han sido totalmente dejados a un lado, como si el dolor norteamericano hubiera opacado el dolor de todos los otros pueblos que sufren".

Desde el otro lado del Atlántico surgen las desavenencias: Rusia, China e Irán no están de acuerdo con la apresurada acusación a esos tres países, Irak, Irán y Corea del Norte, como el eje del mal. La Organización del Tratado del Atlántico Norte (OTAN) se siente otra víctima más de la nueva política de Washington. Después del 11 septiembre, la OTAN quiso colaborar, pero Estados Unidos decidió no contar con esa organización militar: "Estábamos dispuestos a ir a Afganistán, pero no nos dejaron". Resumiendo el pensamiento europeo, el alemán Karl Lammers advirtió a los estadounidenses: "no conviene que ésta sea la regla: ustedes deciden y nosotros seguimos". El ministro de Asuntos Exteriores de Francia, Hubert Vedrine, se expresó sin ambages: "Estamos amenazados hoy día por el nuevo simplismo de reducir todos los problemas del mundo a la simple lucha contra el terrorismo. Esto no es serio y no se puede aceptar esta idea. Si no estamos de acuerdo con la política norteamericana, debemos decirlo. Podemos decirlo y debemos decirlo".

Sin citar nombres concretos, el Secretario de Estado de EE.UU., Colin Powell, quiso dar una respuesta a la irritación europea. "Nosotros creemos en el multilateralismo. Pero cuando se trata de una cuestión de principios, y cuando la comunidad internacional no está de acuerdo con nosotros, no dejamos de hacer lo que estimamos que es 
justo y en nuestro interés, aunque algunos de nuestros amigos no estén de acuerdo" (ECA, 2002; pp. 62-73) Como la tensión interatlántica crece a lo largo del primer trimestre, el 18 de mayo de 2002, Colin Powell critica a los dirigentes europeos, acusándolos de querer "hundir" el plan de guerra contra el terrorismo librada por los Estados Unidos. Powell dice que, pese a la opinión de muchos dirigentes europeos, la política externa norteamericana del presidente George W. Bush ha tenido un gran éxito. El presidente acertó al identificar el "eje del mal" y está consternado al escuchar estas críticas. Powell cree que el antiamericanismo en Europa explica en parte los crecientes sentimientos antieuropeos en la prensa norteamericana. La retórica europea y su permanente crítica está generando su contragolpe.("Colin Powell contre L'Europe". Le Monde, 18-05-02)

Los europeos aprovecharán el viaje de Bush por cuatro países de Europa (Alemania, Rusia, Francia e Italia) para presentarle sus reclamos: ser tratados como aliados y no como "Estados satélites", o incluso como "vasallos". La alianza entre Europa y Estados Unidos se reforzó luego del 11 de septiembre. "Pero las posteriores iniciativas unilaterales de Washington de política exterior, comercial y de defensa han deteriorado el nexo transatlántico, considerado esencial por ambas partes. La definición del eje del mal, la posición sobre Oriente Próximo, el posible ataque a Irak y las medidas proteccionistas para el acero son los puntos álgidos de una política estadounidense que levanta ampollas entre los europeos, que reclaman "ser tratados como aliados, no como vasallos", en frase del ex canciller Helmut Kohl". Mientras concluye el viaje de Bush fluyen una serie de recomendaciones. Bush debe ser prudente si alude a un eventual ataque a Irak, porque pudiera producir anteriores reacciones: "Nos asusta toda posible ampliación del conflicto", dijo Romano Prodi. El consejero de Bush para Defensa, Richard Pearl, recordó que Estados Unidos salvó a Europa en las dos guerras mundiales. "Hoy somos nosotros los amenazados y agradeceríamos un poco de reciprocidad a los europeos".

Se está de acuerdo en que "la relación transatlántica es crucial y no se debe jugar con ella", pero "Europa... intenta elevar sus dosis de autonomía comercial, política y militar", y el propio embajador de Estados Unidos en Bruselas, R. Achnabel, admite que "será más difícil trabajar como socios a medida que la Unión Europea (UE) tenga más independencia al tomar decisiones". Ejemplos de ello son la guerra

La inseguridad: el regulador de la economio mundial 
comercial entre ambos países, la negativa de Washington a la firma de Kioto, la decisión de Washington de aplicar el arancel del $30 \%$ a las importaciones de acero, que les supone una pérdida de 7.500 millones de euros; se reclamarán las indemnizaciones debidas y se llevará ante la sede de la OMC las masivas subvenciones a los granjeros norteamericanos. ("Europa reclama a Bush que trate a sus socios como aliados y no como satélites". El País, 23-05-02)

\section{El nacional integrismo}

Una vez terminado el viaje de Bush por los cuatro países de Europa veremos qué atención y qué respuesta se dará a estos temas, porque al interior de Europa parece que se está dando un serio giro político. También en Europa aparece y crece la inseguridad con el auge del "nacional integrismo". José Vidal-Beneyto dice que "el giro a la derecha en la vida política es un hecho". Este fenómeno se observa en varios países o en zonas de esos países: Italia, Austria, Dinamarca, Flandes, Rumania, Países Bajos, y en Francia con Le Pen. En estos países "han aparecido formaciones políticas con una consistente estructura militante y con una notable presencia electoral y con ciertos núcleos y maneras residuales fascistas"...Estos grupos se situarían en la derecha económica neoliberal, con un cariz de nacional integrismo. "Neoliberal en su afán y prisa por desmontar los servicios públicos y de seguridad social en todos los países en los que participan en coalición de gobierno".

Lo preocupante es la lectura de sus problemas. "Todos ellos responsabilizan de la inseguridad física, y sobre todo vital - ese futuro oscuro y amenazador - al extranjero, en especial de color, y a los agentes exteriores, Europa y mundialización; de ahí que la xenofobia y la negación del extranjero sean uno de los núcleos más irrenunciables de su ideología". Por ello reclaman la instauración de un gobierno fuerte. "Todos ellos hacen de la nación la piedra angular de su construcción ideológica, y de la reivindicación de la soberanía nacional, la primera exigencia de su política". Dado el creciente hiperindividualismo "es inevitable que la pertenencia nacional se viva de forma excluyente y agresiva". ("Derecha europea y nacional integrismo". El País, 11-05-02).

Si la lectura de José Vidal-Beneyto es cierta, y el rumbo de las recientes elecciones parecen confirmarla, la Europa unida se verá sacu- 
dida por fuertes tensiones internas y cómplice o complicada en el grave delito de la xenofobia. En los años de 1990, luego de la descomposición del bloque Este comunista, el foro de La Sorbona, París, alertaba sobre el resurgimiento del nacionalismo en algunos países europeos. Sometidos por largas décadas a un régimen imperial era lógico que surgiera el nacionalismo como una búsqueda de la identidad nacional. Pero al mismo tiempo se advertía que el nacionalismo podía derivar en un movimiento xenófobo entre naciones que buscaban la integración en una Europa unida, Europa, el hogar común. Este problema emergerá en la agenda de la visita de G. W. Bush a Vladimir Putín en Moscú, el 24 de mayo de 2002.

El actual 'nacional integrismo', aparte de sacudir la lograda unidad europea, generará una peligrosa xenofobia contra el extranjero de ultramar. Ese extranjero de ultramar, que no encuentra modo de vida en su país de origen, en buena parte víctima de una mundialización excluyente, y que frecuentemente sigue siendo mano de obra barata en trabajos relegados por el autóctono europeo, sin mayor apoyo de la seguridad social. Volvemos a escuchar las quejas del pobre emigrante del Este europeo, 1990, cuando se sentía rechazado por el opulento Occidente. Esta pandemia de la xenofobia puede acrecentar aún más "la globalización de la ira", que preocupó a los asistentes del foro económico de Davos-Nueva York, febrero 2002. La xenofobia del Norte puede alimentar lógicamente la xenofobia del Tercer Mundo, haciendo que la inseguridad mundial crezca en progresión geométrica. Vivir en mutua inseguridad es vivir en un escenario propicio al terrorismo, con todas sus consecuencias.

\section{Contra la 'economía del terror'}

Quienes hemos sobrevivido guerras prolongadas sabemos qué es terrorismo y por ello nos llama la atención que gobiernos poderosos, que, ni siquiera desde las alturas de las Naciones Unidas, aprobaron misiones y acciones de paz para frenar matanzas y genocidios en varios rincones del mundo (ver La Declaración del Milenio, septiembre de 2002), se vean ahora presas de una obsesión antiterrorista, que se convierta en creciente xenofobia y en culpable olvido de otros terrorismos. Luego de la cumbre de Monterrey, cuya agenda era el alivio de la pobreza, los ministros de Haciendo y jefes de bancos centrales del G-7 se reúnen en Washington, 19 abril 2002. La declaración del G-7 
reza: "Los ministros mantienen su firme decisión de luchar contra la financiación del terrorismo". (FMI - Boletín, 06-05-02; p. 127)

El diario Le Monde dice que se trata de redactar una nueva lista de personas físicas y morales, cuyas cuentas deben ser bloqueadas. La lista será entregada a la ONU. Se trata de una invitación abierta a otros doce países: Arabia Saudita, Emiratos Árabes Unidos, Bahrein, las Bahamas, Suiza, China, la India, Kuwait, Malasia, Pakistán, Brasil y Rusia. La lista es interesante porque, dicen, los fondos terroristas pueden estar depositados y provenir de organizaciones caritativas o de actividades lícitas. A la represión militar se une el control financiero, que supone una actividad prolongada.

El secretario del Tesoro de Estados Unidos, Paul O’Neil, afirma que se han bloqueado unos $\$ 104$ millones, 34 en Estados Unidos y 70 en el resto del mundo, "pero no tenemos una idea de lo que queda por hacer. Estamos lejos de dar por terminado este trabajo; las organizaciones terroristas son inteligentes; ellos constatan que el mundo se ha aliado para interceptar e identificar sus flujos de dinero y buscan medios más sofisticados". El ministro del Tesoro británico, Gordon Brown, afirmó que "la lucha contra el financiamiento del terrorismo sólo ha comenzado. Si el fanatismo es el corazón del terrorismo, las finanzas son sus vasos sanguíneos".

Aquí aparecen algunos datos curiosos. El G-7 desea que se extienda la cooperación para el control financiero del terrorismo. El 'grupo de acción financiera' (GAFI), especializado en la lucha contra el lavado de dinero, ha sido encargado por el G-7, en octubre de 2001, para extender su acción al control de los flujos terroristas. Desde diciembre de 1999 la Convención Internacional para la represión del terrorismo obligaba a perseguir no sólo a los terroristas, sino también a sus prestadores de fondos. Sin embargo, de los 132 países que firmaron el acuerdo, sólo 18 lo han ratificado, de los cuales Francia, recientemente, y el Reino Unido. Los Estados Unidos no lo han hecho todavía. ("Le G-7 relance la lutte contre le financement du terrorisme". Le Monde, 22-04-02). Estados Unidos, que no firmó, se pone ahora de jefe de fila.

\section{Las nuevas amenazas}

El viaje del presidente George W. Bush requiere un breve preludio. La difusión de las imágenes inéditas de Osama Bin Laden han genera- 
do miedo, polémica y mayores medidas precautorias. Miedo e inseguridad comprensible en los ciudadanos norteamericanos, sean ellos autóctonos o inmigrantes, que junto con la incertidumbre puede lastimar el tejido frágil de la convivencia social. Luego del 11 septiembre, el Departamento de Justicia había ordenado interrogar a unas 5.000 personas originarias del Oriente Próximo, pese a no estar relacionados con ningún delito. Esto dio lugar a que muchos inmigrantes se vieran acosados y acusados por otros ciudadanos estadounidenses. (Realidad, 2002, pp. 20-21) La seguridad amenazada puede alentar de nuevo la conducta xenófoba, porque la inédita imagen de Bin Laden alimenta la agresividad. De acuerdo al diario Le Monde, la cadena Al-Jazira afirma que esas imágenes fueron recibidas hace tres o cuatro meses y que no fueron difundidas porque Bin Laden "no dice nada nuevo". La agencia Ansaar dice que obtuvo el vídeo hace cuatro semanas a través de agentes de servicios de información paquistaníes, y que estarían tomadas en el mes de marzo. (Le Monde, 20-05-02) Lo cierto es que aunque Bin Laden "no diga nada nuevo", su simple imagen rediviva reaviva miedos e imágenes que no han cicatrizado.

La imagen inédita ha generado polémica "porque los servicios de inteligencia estaban captando en las últimas scmanas numerosos mensajes de Al Qaeda, con una intensidad similar a la registrada en los meses previos al 11 de septiembre". (El País, 20-05-02) A la polémica se suman las amenazas. Se han levantado serios interrogantes y críticas, demandando si el gobierno tenía suficientes indicios, desde el seis de agosto 2001, sobre los ataques que se perpetrarían el 11 de septiembre. Con fecha 23 de mayo, El País publica un breve reporte: "El agente al que nadie escuchó". Un agente del FBI informó a sus jefes que varios ciudadanos de origen árabe estaban dando clases de aviación en academias privadas. En su informe, de cinco folios, plasmaba sus sospechas: "extremistas árabes pueden estar aprendiendo a pilotar aviones comerciales en EE.UU., con objetivos muy peligrosos, y pedía que se investigaran las academias de vuelo del resto del país, algo que nunca se hizo".

Tanto el presidente Bush, como otros miembros del gobierno, se han apresurado a descalificar estos interrogantes. "Si yo hubiera sabido que el enemigo iba a utilizar aviones para matar esa mañana fatídica del 11 septiembre, yo hubiera hecho todo lo posible para proteger al pueblo norteamericano". El presidente Bush agregó que estos

La inseguridad: el regulador de la economia mundial 
interrogantes eran "jugar con la emoción", y el ministro de Defensa, Donald Rumsfeld, dijo que los terroristas pueden atacar "en cualquier momento, en cualquier lugar, utilizando toda suerte de técnicas, y que físicamente no es posible defender todo el país a la vez, en todo momento del día y de la noche". ("M. Bush tente de désamorcer la polemique sur les attentats". Le Monde, 18-05-02)

El gobierno de Washington procura centrar la atención sobre el peligro de nuevas amenazas. El vicepresidente Dick Cheney declaró que se habían captado unas comunicaciones "vagas, pero perturbadoras" de nuevas amenazas. "Creo que la perspectiva de un futuro ataque a los Estados Unidos es casi cierto. No sabemos si será mañana, la semana próxima o el año siguiente, debido en parte a que hemos logrado desarticular la red". Pueda ser que se trate de ataques como los de Israel: una persona con explosivos en su cintura, desactivados en un lugar público... Uno de los mensajes interceptado se refería a un posible plan de alquilar apartamentos en distintas ciudades de EE.UU., llenarlos con explosivos y hacerlos estallar. Crece la inseguridad pública y privada porque algunos de los mensajes interceptados anuncian un atentado "tan grande como el 11 septiembre o incluso mayor", que causaría "un número altísimo" de víctimas estadounidenses. Dada esta serie de detalles tan tétricos, se ha llegado a pensar que las redes y bastantes prisioneros están tratando de "confundir al espionaje" con datos verosímiles, pero falsos, sobre planes de grandes atentados. ("El vicepresidente Cheney tiene la certeza de que Al Qaeda atacará de nuevo a los EE.UU.". El País, 20-05-01. "Washington met en avant le risque de nouveaux attentats". Le Monde, 20-05-01)

Ciertamente no es viable un mundo en este escenario de amenazas e inseguridad, porque el pánico puede generar más amenazas e inseguridad. Nuestros diarios matutinos, La Prensa Gráfica y El Diario de Hoy, con fecha 22 de mayo y bajo los titulares de amenazas terroristas en Estados Unidos, vuelven sobre el tema del "eje del mal", que será el primer punto de agenda en los discursos de Bush en Europa. El secretario de Defensa, Donald Rumsfeld, habría declarado, una vez más, que Irak, Irán, Siria, Libia y Corea del Norte están desarrollando armas de destrucción masiva (armamento nuclear, químico y biológico) y las estarían suministrando a terroristas con los que están vinculados. Los terroristas no dudarán en usarlas. Cuba también se integraría en la lista, lo que ha generado la consiguiente acusación de Fidel 
Castro: se trata de inventar argumentos para mantener el embargo económico de Estados Unidos a la isla.

Aparte de que en la lista de amenazados aparece la misma estatua de la libertad, Rumsfeld dice que otros intereses norteamericanos pueden ser blanco de ataques en el exterior y en América Latina cunde el secuestro de ciudadanos estadounidenses: 19 casos. "Hay evidencia de la presencia de miembros o simpatizantes de los grupos terroristas Hezbola y Hamas en Chile, Colombia, Venezuela, Panamá...". Este es un dato relativamente nuevo, sobre el que Estados Unidos centra ahora su atención. La verdad es que si atemorizan las amenazas terroristas, también atemorizan las réplicas anunciadas desde Washington. Se globaliza la inseguridad, que se convierte en el problema número uno mundial. Con palabras similares se expresó el presidente español, José María Aznar, anfitrión de la cumbre de Madrid: "El terrorismo es la amenaza directa más importante contra nuestro sistema común de valores, que rechaza nuestras libertades más fundamentales, que busca golpear nuestras economías".

\section{La entrevista de G. W. Bush a la prensa europea}

En este escenario se inicia el viaje de George W. Bush por cuatro países de Europa (Alemania, Rusia, Francia e Italia), luego de conceder una entrevista a cuatro diarios de esos países. Esta conferencia abierta preludia el mensaje que Bush lleva a Europa y los temas mayores que allí se tratarán. Tanto Le Monde como El País ponen similar título a la entrevista: "Bush exhorta a Europa a combatir el terror global". George W. Bush y su equipo han escogido como primera escala Berlín, por ser un símbolo de la "lucha contra el terrorismo" luego de los grandes combates de europeos y norteamericanos contra el "nazismo" y después el "comunismo". Ahora se trata de la "nueva amenaza global". Por supuesto que George W. Bush no va a poner en la lista al neoliberalismo mundial. He aquí un resumen de las preguntas y respuestas:

P. ¿Hay algo que no funciona en las relaciones entre Estados Unidos y Europa?

R. Son más las cosas que nos unen que las que nos separan. El amor a la libertad es un vínculo poderoso. Y estamos también ligados por valores comunes: el derecho, los poderes constitucionales, el mer- 
cado. Tenemos así mismo que resolver los problemas comunes, lo que es más importante que cualquier disputa que pueda surgir. Combatir el terrorismo es una causa común que nos une poderosamente. Naturalmente que hay desacuerdos. Tenemos diferencias en el terreno del comercio, pero porque el comercio entre nosotros es considerable. Es algo normal y no es, sin duda, algo que afecte mi visión de nuestra alianza.

P. ¿Está la OTAN condenada a desaparecer? Y, en caso contrario, ¿para qué servirá?

R. La OTAN es más necesaria que nunca por varios motivos. La naturaleza de la amenaza a la que colectivamente nos tenemos que enfrentar ha cambiado. La OTAN, que une países que aman la paz, debe cambiar su objetivo y desarrollar sus capacidades para ser capaz de combatir las amenazas a las que nos enfrentamos. La OTAN es, por tanto, muy necesaria ahora. Tenemos que trabajar con ella para que se usen mejor sus recursos, para definir sus estrategias y para que una alianza ampliada pueda hacer frente a la nueva amenaza correctamente.

P. ¿Le preocupa la diferencia entre la capacidad militar de Estados Unidos y la de sus aliados europeos?

R. Es un problema, pero podrá superarse en el tiempo. Rusia ya no es una amenaza. La OTAN debe adaptar sus medios y su presupuesto a las nuevas amenazas. Lo repito, voy a Europa como amigo, deseoso de trabajar con ella en nuestros objetivos comunes. Y la guerra contra el terrorismo exige una cooperación significativa.

P. ¿El Consejo OTAN-Rusia da a Rusia el derecho a cuestionar las decisiones de la OTAN?

R. No da a Rusia ningún derecho de veto sobre las acciones militares. Reconoce que Rusia puede ser un socio importante para una Europa pacífica y permite trabajar con ella sobre medidas para evitar la proliferación nuclear y contra el terrorismo. Rusia tiene que hacer frente a las mismas amenazas que Italia, Francia, Alemania y Estados Unidos. Puede parecer que no es así, pero les aseguro que la amenaza es absolutamente real.

P. ¿En su opinión, Irak está hoy incapacitado para actuar o piensa que es urgente actuar contra Saddam Hussein? 
R. Soy un hombre paciente, pero también tengo determinación. Contenerse (contained) es una palabra que no es adecuada cuando nos enfrentamos a alguien con la capacidad de golpear con un arma de destrucción masiva. Eso me preocupa profundamente. Sé que mis declaraciones sobre este país han provocado angustia, pero mi responsabilidad es hablar tan claramente como pueda y seguiré haciéndolo.

P. ¿Es esta amenaza la que ha llevado al vicepresidente Richard Cheney a decir que la reanudación de las inspecciones de la ONU no será suficiente?

R. Esperamos que el gobierno iraquí permita inspecciones completas y sin límites. Nos encontramos con un hombre que ha rechazado las inspecciones durante años. Pienso que el mundo entero debería preguntárselo.

P. ¿Las declaraciones realizadas en los últimos dias sobre amenazas terroristas, sobre todo por el vicepresidente Cheney, son una advertencia general o son informaciones precisas sobre un riesgo inminente?

R. El director del FBI especuló sobre la base de informaciones que indicaban que la red Al Qaeda está todavía activa, que conspira, elabora planes, busca cómo atacarnos. Especulaba al afirmar que no le sorprendería que volviesen a atacarnos. Pero dudo mucho que diésemos publicidad a una amenaza de este tipo. Naturalmente, las personas cuya vida estuviese en peligro serían informadas. Algunas de ellas no están dirigidas contra Estados Unidos, sino contra nuestros amigos. Estoy seguro de haber leído amenazas contra los cuatro países que voy a visitar. Antes incluso de que me lleguen a mí, esas informaciones son enviadas a los países afectados. No quiero ser alarmista, pero esa gente es implacable. Cuando digo que la mejor defensa es el ataque, lo pienso realmente. La mejor manera de proteger a nuestros pueblos es perseguir a esa gente hasta el final. (El País, 23-05-02)

El lector podrá apreciar que el presidente George W. Bush está bien asesorado en cada una de sus respuestas a los cuatro corresponsales y que su mensaje a Europa es claro: debemos unirnos contra el enemigo común y mundial. Pero frente a los cuatro jefes de estado saldrán otros temas más ambiguos: los planes para atacar a Irak (donde habrá un cierto cambio de agujas), el protocolo de Kioto, el pro- 
teccionismo comercial. Con Putin se llevará a cabo el acuerdo de desarme nuclear, donde parece que no todo queda claro; las relaciones con Irán y también el tema del petróleo, siendo Rusia un posible abastecedor de Europa occidental y de los Estados Unidos. Con Jacques Chirac saldrá a relucir el tema del Oriente Próximo y la ampliación de la OTAN. En Roma, asistirá Bush a la cumbre extraordinaria de la OTAN, y luego será recibido por el Papa. No podían faltar algunos manifestantes pacíficos.

\section{El viaje de George W. por Europa}

Una vez adelantada la entrevista de George W. Bush y que su mensaje mayor será pedir a los jefes de Estado su integración al combate del enemigo común, el terrorismo, podemos recoger algunos hechos y discursos más relevantes. La primera estación, Alemania.

Cuando George W. Bush dijo en el Bundestag alemán que Estados Unidos y Alemania vencerían, juntos, a los "enemigos de la libertad", tres diputados neocomunistas, sin decir palabra, desplegaron una pancarta donde se leía: "Bush y Schröder, cesad vuestras guerras", y abandonaron la asamblea. Más directo, con palabras bien medidas, fue el discurso del presidente del Bundestag, W. Thierse, del partido socialdemócrata. Saludó cordialmente al presidente Bush, recordando el papel de los Estados Unidos en el restablecimiento de la democracia alemana y en su recuperación económica de postguerra. Pero agregó, en forma cuidadosa, una serie de reproches a Norteamérica, más proclive al uso de la fuerza y de la acción solitaria: "En un mundo globalizado, cada vez menos los problemas afectan a un solo país, y un solo país no los puede resolver. Más pronto que tarde, todos sentiremos las consecuencias de la integración económica mundial, de la indigencia de los países pobres y del uso irresponsable de los recursos naturales. Necesitamos coaliciones contra la pobreza; necesitamos acciones coordinadas contra el daño hecho a la biosfera. Esperamos muy de veras, Señor Presidente, que estemos en capacidad de seguir juntos la ruta trazada por el protocolo de Kioto... Ninguna coalición es más urgente que la de la paz mundial".

Por su parte, G. Schröder había indicado que la solidaridad alemana 'ilimitada' en la lucha contra el terrorismo no implicaba un acuerdo para una operación militar contra Bagdad y su 'dictador', sin un mandato de las Naciones Unidas. Bush tranquilizó a los alemanes al decir 
en conferencia de prensa que él no tenía en su escritorio "ningún plan de guerra" contra Irak. "Debemos utilizar todos los medios a nuestra disposición para tratar el problema de Saddam Hussein", dando a entender que no se excluía la posibilidad de evitar una acción militar. Bush promete consultar a los aliados europeos en caso de atacar a Irak. Tanto Le Monde como El País comentan esta noticia, con fecha 24 de mayo, y El País agrega un día después: "El Pentágono presiona a la Casa Blanca para que descarte una invasión a Irak". "Los responsables militares no son partidarios de una invasión o, al menos, no hasta bien entrado el año próximo. El Pentágono teme que una invasión a gran escala, como parece haber anticipado el Gobierno en los últimos meses, pueda causar miles de bajas entre los soldados estadounidenses...Según Rumsfeld, sería 'estúpido' discutir en público sobre estrategias militares, pero manifestó ayer que Estados Unidos "no tiene planes" para invadir Irak, "ni ningún otro país".

Si el gobierno iraquí, por su parte, no dice nada, Irán sí ha protestado contra "los informes del terrorismo mundial del 2001", presentados por los Estados Unidos y más recientemente por D. Rumsfeld, "porque no tienen ningún fundamento. Estas acusaciones son propias de la política hostil de los Estados Unidos respecto a Irán... y aprovechan los sucesos del 11 de septiembre para imponer sus ilógicas visiones en otros países". Hamid Reza Assefi, representante del Ministerio de Asuntos Exteriores de Irán, afirma que ellos preconizan "una campaña contra el terrorismo bajo la égida de las Naciones Unidas". Le Monde aprovecha la oportunidad para citar a Matt Levitt, antiguo agente del FBI, especializado en lucha antiterrorista, quien opina que el gobierno de Bush aprovecha toda esta publicidad de amenazas terroristas para distraer la atención sobre los descuidos y lagunas de su gestión en prevenir los atentados del 11 de septiembre. (L'Iran conteste 'Les données du terrorisme mondial en 2001". Le Monde, 26-05-02) Otros agregan que esta publicidad pretende silenciar los enredos de la Casa Blanca en la quiebra de la Enron.

\section{El pacto Moscú - Washington}

A nivel internacional y de cara a la nueva geopolítica tienen mayor transcendencia los acuerdos firmados en Moscú por George W. Bush y Vladimir Putin. La agenda es multiforme y ambos mandatarios esperan obtener grandes beneficios de alcance geopolítico para uno y eco- 
nómicos para el otro. El primer acuerdo, cuyo borrador ya estaba pactado, es la reducción de los arsenales nucleares de ambas potencias a un nivel máximo de 2.200 ojivas de aquí al 2012. Un descenso significativo de las 6.000 hoy existentes. Cuestiones técnicas, que los técnicos entenderán, Norteamérica anuncia que almacenará sin desmantelar las ojivas retiradas, mientras que Rusia guarda la posibilidad de instalar múltiples cabezas en los misiles conservados. Para Rusia este pacto es ventajoso porque no cuenta con recursos financieros para mantener su actual arsenal y porque espera nuevas ayudas económicas luego de este acuerdo que "pone fin a la guerra fría". Así han interpretado ambos mandatarios la firma de este tratado. La víspera de la llegada de Bush a Moscú Putín dijo que Rusia y los Estados Unidos han logrado "desde hace un año crear un clima de mutua confianza y comprensión, demostrando que nuestros países no son adversarios". ("Vladimir Putin consacre son raprochement avec les Etats Unis". Le Monde, 23-05-02)

Se iniciaría así la era de las concesiones económicas a cambio de la nueva alianza política. Para George W. Bush, el tema y el logro central es "la lucha contra el terrorismo". Muchas cosas parecen haber cambiado de 1996 a nuestros días. En diciembre de 1991 se firma el decreto de Minsk, que consagra la extinción de la URSS, del Pacto de Varsovia y del bloque del Este. En 1996 la Duma, cámara baja de Rusia, aprueba por mayoría de votos un decreto, que anularía el decreto de Minsk de 1991, estableciendo que Rusia retenía un poder de control político de Eurasia, de manera que las ex repúblicas soviéticas no podrían establecer alianzas políticas con terceros países. Si bien este decreto no tenía validez jurídica, reflejaba la voluntad de muchos diputados y del cuerpo militar de Rusia, como reacción a la presencia de la OTAN en la guerra de Serbia-Kosovo. La geopolítica da un giro de 180 grados.

La "guerra contra el terrorismo", y los recursos petrolíferos, centran la atención de ambos mandatarios en los países de Asia Central y del Cáucaso, sacudidos por múltiples conflictos nacionalistas y terreno abierto a toda clase de tráficos. Ambos países, Estados Unidos y Rusia, actuarán "conjuntamente" para resolver muchos conflictos regionales, entre otros el caso de Chechenia, y para favorecer la explotación de los recursos energéticos del Caspio. Esto significaba dar un derecho de inspección a los Estados Unidos sobre una amplia zona 
que había sido el coto cerrado de Rusia. En la declaración conjunta sobre "la cooperación contra el terrorismo" ambos mandatarios juzgan que "la soberanía, la estabilidad durable, la prosperidad y el desarrollo democrático futuro de los Estados de Asia Central sirven los intereses de los Estados Unidos y de Rusia". Se hace mención especial de Georgia, donde han surgido "elementos" terroristas, y donde ya han comenzado a llegar instructores norteamericanos para adiestrar a las fuerzas nacionales. El texto anuncia también la organización de parte de Estados Unidos de una conferencia regional sobre el terrorismo, con la participación de los Estados de Asia Central y del Cáucaso, Afganistán, Turquía, China y Rusia, en el mes de junio.

Se suman dos razones. Los conflictos actuales en toda la región del Cáucaso y la imprevisibilidad de Asia central amenazan la lucha mundial contra el terrorismo, y la seguridad norteamericana, porque si estas regiones se hunden en el caos y en conflictos violentos contra civiles, pueden convertirse en terreno propicio para los extremistas y para la red $\mathrm{Al}$ Qaeda. Además, en esa región están en juego los recursos petroleros. Ambos mandatarios han firmado un pacto energético, "uniendo sus esfuerzos para desarrollar los vastos recursos energéticos de Rusia y de la región del Caspio". La cooperación energética ruso-americana en Rusia y en las zonas fronterizas a Rusia, "refuerzan la soberanía, el bienestar, la cooperación y la integración en la economía mundial de todos los Estados participantes". ("Les Etats Unis et la Russie scellent une nouvelle alliance". Le Monde, 25-05-02)

Rusia mantiene un "diálogo energético" con Europa, que es su principal cliente, mientras que Estados Unidos sólo la adquiere un $0,2 \%$ de sus importaciones energéticas. Se espera que esta proporción se incremente con los acuerdos de inversiones para el desarrollo y modernización del sector energético en Rusia, Siberia oriental y lejano oriente. La inversión se extenderá también a la modernización de la infraestructura portuaria y del transporte del gas y petróleo. Dos compañías norteamericanas, Chevron Texaco y Exxon Mobil, han firmado contratos para el transporte del crudo a través del mar Caspio y para la modernización de las plataformas marinas de extracción del crudo. Otras compañías invertirán en la prolongación del oleoducto que atraviesa las zonas conflictivas de Asia central. La geopolítica se une a la geoeconomía para lograr un abastecimiento más estable para Europa y también los Estados Unidos. 
Otros logros económicos quedan como puntos de agenda pendientes. Rusia sostiene una deuda externa de $\$ 138.000$ millones. El pasado mes de abril, Putin logró que Gerhard Schröder redujera la deuda rusa a Alemania, de 6.000 millones de euros, a sólo 500 millones. El FMI se ha resistido durante años a hacer nuevos préstamos a Rusia mientras el gobierno no tomara medidas más drásticas para frenar la salida de esos fondos a cuentas externas de los "nuevos zares" o personas allegadas al ex presidente Boris Yeltsin. Putin espera que los nuevos acuerdos político-económicos puedan abrir la válvula de nuevos créditos. Esto significa que Putin debe hacer un gran esfuerzo por afianzar su economía, en estado bastante caótico luego del ascenso de los nuevos oligarcas en la era Yeltsin, así como una modernización política asentada en los principios democráticos del respeto de los derechos humanos, de las minorías étnicas, de la libertad de prensa, de la separación de poderes y de la economía de mercado. Todo esto le abriría las puertas para que Estados Unidos apoyara el ingreso de Rusia en la Organización Mundial del Comercio. Ahora Rusia forma parte del Consejo OTAN-Rusia, que se acaba de firmar en Roma el 28 de mayo. Bush logró su objetivo principal de englobar a Rusia y Asia central en el pacto antiterrorista y Putín espera obtener amplias ventajas económicas, problema mayor de la 'gran Madre Rusia'.("Vladimir Poutine consacre son raprochement avec les Etats Unis". Le Monde, 23-05-02. "Bush y Putin refuerzan su alianza con un gran acuerdo de venta de petróleo". El País, 25-05-02)

\section{De paso por París. Más acuerdos que diferencias}

La reunión de George W. Bush con Jacques Chirac ha sido, en expresión del presidente francés, "al mismo tiempo densa, franca y amigable; ambos tenemos los mismos puntos de vista". Respecto a la lucha antiterrorista "nos situamos en la misma perspectiva y en la misma determinación de hacer todo lo posible para erradicar el terrorismo. Estamos conscientes de que siempre está presente, que puede en cualquier momento atacar en cualquier lugar y que requiere de nuestra parte, especialmente de los dirigentes de todas las naciones, el mayor empeño por erradicarlo". Bush agregó: "erradicar las fuentes de financiamiento del terrorismo y cerrarle el espacio donde pueda replegarse».

Dos puntos merecen atención: impedir que Pakistán traspase las líneas fronterizas, que pueden fomentar el terrorismo, y poner todos 
los medios para que se reanude el diálogo entre Israel y Palestina. Salieron a relucir algunas divergencias menores, según Chirac, como los nuevos derechos de aduana de Estados Unidos al acero y su política de subvenciones agrarias. Ambos jefes de Estado estaban de acuerdo en que Estados Unidos y Europa son las primeras potencias económicas del mundo; "Por la economía viene el progreso social y el poder político se expresa a través del poder económico". Tenemos valores compartidos y "esto es lo esencial, el verdadero equilibrio del mundo hoy, y todos queremos que se mantenga este equilibrio". ("Bush et Chirac contre le terrorisme". Le Monde, 26-05-02)

\section{El final de la guerra fría}

Si en el presente viaje George W. Bush no hizo parada en Londres, Tony Blair quiso dejar estampada su lectura sobre la creación del Consejo OTAN-Rusia, en una conferencia que El País titula: El final de la guerra fría. Algunos de sus párrafos nos aclaran el papel y el poder que Rusia tiene en este Consejo y la reestructuración de objetivos de la OTAN ampliada. La palabra que aparece varias veces es "la seguridad del mundo", lo que, leyendo al trasluz, significa la "inseguridad que vive el mundo", especialmente los más poderosos del mundo, reunidos ahora en Roma. Si la OTAN se creó para responder a la amenaza de la Unión Soviética, la firma de un tratado Rusia-OTAN quiere decir que el mundo ha cambiado de enemigo, pero no de inseguridad:

El nuevo Consejo no es un foro de debate. Es un ámbito en el que se materializa el ideal de cooperación en materia de 'seguridad'. Rusia ocupará un lugar, por primera vez, como socio pleno y como igual. El nuevo Consejo de 20 socios pondrá los cimientos de una colaboración en múltiples aspectos. Debe destacarse que cuando se hayan alcanzado decisiones conjuntas de forma consensuada, las mismas serán vinculantes para todos los miembros del Consejo OTAN-Rusia. Esto exigirá un 'cambio de mentalidad por parte de todos nosotros', un nuevo nivel de confianza, y la voluntad de unirnos y mantenernos fieles a las políticas comunes de los veinte.

El nuevo Consejo OTAN-Rusia conducirá, sin duda alguna, a una mayor cooperación militar. De hecho, este es uno de los propósitos expresos de la iniciativa. Se iniciará un ambicioso programa de 
trabajo en el que tendrá cabida la cooperación en los ámbitos de la lucha antiterrorista, la gestión de la crisis, la no proliferación de armas y las emergencias civiles. Confío y espero que podamos desarrollar este programa inicial a medida que la relación y los hábitos de cooperación vayan creciendo. El nuevo Consejo no vendrá a sustituir al Consejo Atlántico Norte. Rusia no va a incorporarse a la OTAN, ni tampoco dispondrá de capacidad para vetar el derecho de la OTAN a decidir y actuar de manera independiente. En cuanto a la OTAN, ésta continuará cumpliendo su crucial función de garante de la seguridad de Europa y seguirá siendo la principal plataforma multilateral de las relaciones transatlánticas. La transformación de las relaciones de la OTAN con Rusia no sólo demuestra la importancia permanente de la OTAN sino también la capacidad de la misma para adaptarse a la cambiante situación en lo que a 'seguridad' respecta. Me consta que existirán obstáculos que habrá que superar y recelos, que vienen de atrás, que deberán dejarse a un lado. Sin embargo, por las conversaciones que he mantenido con otros dirigentes antes de esta importante reunión, sé que existe una inmensa voluntad común de aprovechar esta oportunidad que se nos presenta a todos" (El País, 28-05-02).

Si hemos entendido bien la conferencia de Blair, el nuevo Consejo OTAN-Rusia sería una alianza donde no habría un "primus inter pares" que marcará el paso a seguir por los demás, aunque sí parece quedar un puesto para un 'invitado de piedra', que, por cierto, puede aportar y recibir bastante. "Bush estaría forjando una nueva y más amplia coalición internacional, la OTAN se estaría preparando para las nuevas amenazas y Putin aprovecharía la ocasión para acercarse a Occidente, modernizar su economía y su ejército y recibir carta blanca para actuar en Chechenia, 'frente al terrorismo y separatismo', como dijo el secretario general de la OTAN, George Robinson". Se entierra la guerra fría y se continúa con la paz violenta.

"El pacto con Rusia abre a la OTAN la colaboración frente a nuevas amenazas para las que no está preparada. Ambas partes intercambiarán datos sobre redes terroristas y formación de unidades de elite, así como sobre sistemas para defenderse de ataques incontrolados con misiles de corto alcance o armas químicas". Bush dijo: "La OTAN es más necesaria que nunca. Tenemos que compartir las informaciones, seguir pistas, evitar que los asesinos actúen y arrestar- 
los. La OTAN permite eso". A Rusia el Consejo con la OTAN "le confiere un nuevo estatus global", un reconocimiento de ser todavía una potencia, como dijo el presidente Berlusconi. Por su parte, Putin comunicó a la OTAN que aprovechará el acuerdo para reformar y modernizar el Ejército y sus mandos". ("La OTAN intenta superar con Rusia su crisis de identidad". El País, 28-05-02)

\section{La Declaración de Roma}

La así llamada "Declaración de Roma" se abre frente a un "frontispicio' no muy halagador: "Vivimos en un mundo nuevo ... donde nuevas amenazas y desafíos exigen respuestas cada vez más unidas. Por esta razón los Estados miembros de la OTAN y la Federación de Rusia abrimos un nuevo capítulo en nuestras relaciones..." Siguen los numerales que establecen los acuerdos de la alianza, de los cuales extractamos algunos detalles informativos. Se trata de participantes iguales en los temas de interés común. Se aplicará el 'principio del consenso'. Será presidido por el secretario general de la OTAN. Se reunirá dos veces al año al nivel de ministros de asuntos exteriores o ministros de defensa, y una vez al mes al nivel de embajadores.

El presidente Bush pidió a los miembros de la OTAN modernizar sus estructuras de defensa para hacer frente a las verdaderas amenazas del siglo XXI, sin que ello signifique derroches inapropiados. Bush se refería a un programa propuesto pos algunos parlamentarias en Estados Unidos. "Debemos gastar el dinero en sistemas de armamento necesarios, y no en aquellos que interesan 'políticamente', a comenzar por el (cañón) Crusader”. G. Robertson, secretario general de la OTAN, se ha pronunciado por una modernización de su armamento: "Los europeos deben hacer más, gastar más y más sabiamente y los Estados Unidos deben compartir su tecnología y abrir los mercados de exportaciones para propiciar una reorganización transatlántica".

Pese a algunas objeciones de Rusia, la OTAN invitará a otras naciones a unirse a la Alianza, declaró C. Powell, como se discutirá en Praga, noviembre 2002. A los nueve candidatos actuales (Lituania, Letonia, Estonia, Eslovaquia, Rumania, Bulgaria, Macedonia y Albania) se sumará Ucrania, el vecino más potente de Rusia. C. Powell declaró que esta larga ronda de Bush ha sido "un viaje histórico coronado con un gran éxito", que ha consolidado las "sólidas" relaciones de Washington y Europa. No quiere decir esto que no tengamos algu-

Lo inseguridad: el regulador de lo economia mundial 
nos desacuerdos, sobre el protocolo de Kioto, la reciente creación de la Corte Penal Internacional. "Nosotros discutimos con nuestros amigos europeos y no se puede hablar de unilateralismo porque no se esté de acuerdo. Nosotros somos parte de una gran alianza, aunque esto no signifique que estemos de acuerdo en todo. Ahora nos regresamos dejando a los europeos una mejor comprensión (de nuestra posición) y de la manera en que procedemos. Nosotros consultamos, nosotros hablamos, nosotros nos reunimos". ("La création du Conseil OTAN-Russie: une coopération de Vancouver a Vladivostok". Le Monde, 28-05-02)

A la hora de los brindis, casi todos los jefes de Estado levantaron su copa y echaron su estribillo: "El terrorismo tiene unos medios excepcionales que requieren una respuesta excepcional", declaró J. Chirac. "El pueblo británico ya no teme al ruso, pero los dos tememos al terrorismo", señaló T. Blair. "No podéis vencernos, no tenéis ninguna oportunidad", espetó Berlusconi a los teroristas. "Los valores no se defienden solos. No debemos esperar sentados a ser agredidos", añadió J. M. Aznar. La mayoría de líderes destacaron el protagonismo de Rusia, de Putin en particular, que, aparte de comprometerse a la defensa de la democracia y la libertad, tendrá que enfrentar algunos recelos internos de la clase militar. Puesto que Rusia se une a este esfuerzo europeo, Putin exigió un 'respeto recíproco': “No podemos pensar Rusia fuera de Europa". ("Rusia y la OTAN pactan una estrategia contra el terrorismo y los nuevos riesgos". El País, 29-05-02)

\section{La postdata de los olvidados: la cumbre de Madrid}

Comenzamos diciendo que el mundo de hoy se parece a un tablero de ajedrez donde todas las partidas se juegan desde los cuatro costados. Con la aprobación del Consejo Rusia-OTAN, el Atlántico Norte se une para inyectar una dosis de seguridad a la inseguridad que dicen les amenaza en cualquier tiempo y lugar. Pero ese binomio seguridad inseguridad los repliega sobre sí mismos, olvidando la inseguridad vital y económica en que viven otros países de ultramar. Un botón de muestra ha sido la cumbre de Madrid, donde unos cincuenta jefes de Estado europeos y latinoamericanos se reunieron con miras a establecer estrechas relaciones políticas y económicas entre ambos continentes. La cumbre tuvo lugar el 17 de mayo, en vísperas de las reuniones que acabamos de comentar y cuyos borradores eran conocidos. Por ello, en Madrid también se hablará del terrorismo y de inseguridad. 
En Madrid será el presidente de Brasil, Fernando Henrique Cardoso, quien hable de la "otra inseguridad", lanzando el puente entre la esperanza y el miedo, pidiendo que los sucesos del 11 septiembre no ofusquen la capacidad de los líderes de buscar un desarrollo equilibrado. "Comprendemos las reacciones más que justificadas a las amenazas del terrorismo y del uso de armas de destrucción masiva. Pero no queremos que, movidas por el miedo, las grandes potencias sustituyan la agenda de la esperanza, obsesionándose únicamente por el tema de la seguridad". Cardoso dirá que "la agenda de la esperanza, un comercio abierto, una nueva arquitectura financiera, la lucha contra la pobreza y la exclusión social y cultural", es el planteamiento de los países latinoamericanos. "Hoy, las cuestiones de seguridad, la búsqueda de mecanismos de gobernación en el contexto de la globalización, el tratamiento de temas de alianza universal, imponen que no pensemos exclusivamente en los intereses de los propios Estados, sino también y fundamentalmente que pensemos en la humanidad. Tenemos ante nosotros la tarea de construir una ciudad planetaria. Puede que sea un sueño, una utopía. Sin embargo, es una utopía necesaria. Es un incentivo y una inspiración".

Este orden internacional ces posible a través de un proceso de globalización? "Hay una preocupación respecto a la sinceridad del compromiso de la comunidad internacional con el libre comercio y con la construcción de un orden propicio al progreso de todos. Hay una percepción de que el proteccionismo ha sido condenado como instrumento de desarrollo de los más pobres tan sólo para convertirse en instrumento de defensa de los privilegios de los más ricos". Este fue uno de los puntos candentes en la reunión de la OMC de Qatar y vuelve a plantearse en la cumbre de Madrid. "El comercio no es un fin en sí mismo. Debe generar empleos, eliminar las iniquidades, transferir tecnología... La eficacia que nos interesa no es la de la fuerza, sino la que proviene de la libre unión de voluntades. Esta eficacia no existe sin legitimidad. Europa puede contribuir a que el sistema internacional se vuelva más solidario, más representativo y, por ende, más legítimo y eficaz". ("El presidente brasileño Cardoso pide que Europa no se obsesione por la seguridad". El País, 18-05-02)

El discurso de Cardoso generó aprobaciones verbales contra el gran ausente, sin llegar a compromisos reales: "La Unión Europea y América Latina denuncian las prácticas proteccionistas estadounidenses en 
el comercio mundial". En la declaración firmada por los 15 países de Europa y los 33 latino- americanos se aprueba: "Rechazar todas las medidas de carácter unilateral y efecto extraterritorial que son contrarias al derecho internacional y a las reglas del libre comercio comúnmente aceptadas. Concordamos en que este tipo de prácticas constituye una seria amenaza contra el multilateralismo". Al igual que en Monterrey, el presidente de Francia, J. Chirac, afirmó que "es necesario humanizar la globalización. Y ciertamente, las recientes medidas adoptadas por los Estados Unidos, además de lamentables, van en sentido contrario de lo que queremos". ("La cumbre de Madrid critica el unilateralismo de Estados Unidos". El País, 18-05-02)

Antes de la cumbre de Madrid ya se habían elevado voces críticas contra los masivos subsidios agrícolas aprobados por el gobierno de Washington a sus granjeros. Guillermo Perry, del Banco Mundial, considera que esta medida "afectará muy sensiblemente las exportaciones en América Latina. Lo que es peor aún, envía una mala señal sobre el compromiso de los Estados Unidos con el libre comercio, a escala mundial y hemisférica". Un funcionario europeo, residente en Washington, dijo: ""Es un desastre. Estados Unidos nos ha criticado durante años por nuestra política agrícola (europea), y ahora ese mismo país está volviendo a las políticas retrógradas de los $80 "$. El premio Nobel de Economía, Joseph Stiglitz, calificó esta medida como una hipocresía: "Es la perfecta ilustración de la hipocresía de la administración Bush sobre la liberalización del comercio; el comercio es algo bueno, no las importaciones. El total de las subvenciones agrícolas en el Norte sobrepasa en la actualidad el PIB del Africa subsahariana. Los países del Sur no tienen ninguna oportunidad de ser competitivos en esas condiciones". ("América Latina preocupada por subsidios agrícolas”. La Prensa Gráfica, 00-57-02; p. 41)

La polémica continúa entre la Unión Europea y los Estados Unidos. Los europeos se resisten a pagar los costos de la ley de negociación de acuerdos comerciales (fast track), si la aprobación del Congreso está condicionada a las medidas proteccionistas sobre el acero y la Ley Agrícola. El debate se había iniciado entre el representante europeo, Pascal Lamy, y el norteamericano, Robert Zoellick, quien sostiene que tanto la Ley Agrícola, aprobada por el Congreso, así como los aranceles del $30 \%$ para el acero, son compatibles con las reglas de la OMC. ("Unión Europea contra subsidios de E.U.A." La Prensa Grá- 
fica, 22-05-02) Precisamente en la OMC de Qatar se criticaron estas asimetrías unilaterales del Norte, comprendida la Unión Europea, que J. Stiglitz llama hipocresía. (Realidad, 2002, pp. 14-19) Con la misma fecha, La Prensa Gráfica publica otro titular: "Países ricos deben quitar subsidios". Ahora es México, sede de un próximo encuentro en que se discutirán las resoluciones de la conferencia de Qatar, quien planteará los problemas creados por estas decisiones de los países ricos. "Casi puedo asegurar que hay un clamor generalizado, no sólo a los Estados Unidos, sino a la Unión Europea y Japón, que tienen que ser eliminados los subsidios a la importación y a la exportación agropecuaria", dijo el representante de México. (La Prensa Gráfica,. 22-05-02; p. 51 )

Mientras que en Centroamérica, especialmente en El Salvador, se ha celebrado la aprobación votada en el Senado de Estados Unidos, concediendo al presidente George W. Bush la autorización de firmar tratados de libre comercio, quedando pendiente la elaboración del documento final, esta aprobación ha sido recibida con "escepticismo en Brasil y Argentina". Conviene recordar que estos dos países han protestado, junto con la Unión Europea y Rusia, por los aranceles levantados a sus exportaciones de acero. "Esta decisión sobre el TPA va a terminar afectando las negociaciones en toda la Organización Mundial del Comercio. Y hace que el ALCA sea muy difícil porque los otros países sienten que no tienen libertad de negociar", dijo José A. De Castro, director de la Asociación del Comercio Exterior de Brasil. Con similar o mayor razón reclama Enrique Mantilla, presidente de la Cámara Argentina de exportadores, país que en su actual quiebra financiera se ve doblemente dañado por los aranceles del acero y la Ley Agrícola. "Si se mira, no sólo la lista de productos no incluidos (en la iniciativa), sino también la nueva ley de subsidios agrícolas, se comienza a pensar que los legisladores estadounidenses son poco claros sobre qué tipo de papel quieren jugar para alentar el libre comercio". A estas se agregan las 'dudas chilenas', uniéndose a la crítica de otros socios comerciales que creen que Estados Unidos aplica estas leyes injustamente. ("No toda Latinoamérica aplaude la TPA". La Prensa Gráfica, 25-05-02; p.33)

Regresando a la cumbre latino-europea de Madrid, los delegados de nuestro continente pedían una "transformación cualitativa del comercio internacional". La conferencia de Qatar había generado esperanza,

Lo inseguridad: el regulador de la economia mundial 
pero el "proteccionismo y las prácticas desleales siguen amenazando el desarrollo de nuestros países. No hemos venido a pedir dinero a Madrid, sino una apertura para nuestros productos, que son mejores que los que reciben subvenciones tanto en Europa como en Estados Unidos. Si América Latina pudiera beneficiarse de una libertad de comercio desaparecería la deuda externa latinoamericana". Los jefes de Estado europeos, salvo una o dos excepciones, colocaron estas peticiones en el congelador, hasta el año 2004, en espera de que se terminen las negociaciones pendientes de la OMC de Doha, Qatar. A partir de esa fecha se podrán discutir nuevas líneas de liberalización de intercambios entre ambos continentes.

El anfitrión español, José María Aznar, que abrió la conferencia con el tema del terrorismo, problema número uno, clausuró el encuentro expresando una "razonable satisfacción", luego de "una larga y productiva jornada de trabajo", aceptando "ser consciente de las dificultades en el largo camino a recorrer". Mezclando el agua con el vino, Aznar destacó entre los logros el compromiso de la lucha contra el terrorismo y el narcotráfico, la aprobación de un programa europeo de becas para postgrados latinoamericanos, insistiendo en que hay que seguir el camino de la apertura comercial para evitar cualquier actitud proteccionista". En resumen: terrorismo y palabras huecas. ("Un sommet de Madrid décevant pour l' Amérique Latine". Le Monde, 18-05-02)

Con ocasión de la conferencia sobre Transición y Consolidación Democrática, tenida en Madrid, el 28 de octubre, Mikhail Gorbachov, padre de la Perestroika, dijo que "las víctimas de los atentados del 11 de septiembre en los Estados Unidos no habrían muerto en vano si el mundo aprovecha la ocasión para mirarse en el espejo y reflexionar sobre sí mismo y establecer un compromiso moral sin caer en el pánico". Triste es decir que no ha jugado el compromiso moral, sino el pánico. Surge el nacional integrismo en varias regiones o estados de Europa, con su secuencia de xenofobia del inmigrante. Resurge una guerra fría, en que se pacta una nueva carrera armamentística en el bloque Norte, al mismo tiempo que sus economías no acaban de componerse y se repiten las fraudulentas quiebras empresariales. Con la inseguridad crece la insolidaridad que se traduce en una paz violenta hacia el tercer mundo.

Volvemos a leer las palabras de Fernando Cardoso: "Comprendemos las reacciones más que justificadas a las amenazas del terrorismo 
y del uso de armas de destrucción masiva. Pero no queremos que, movidas por el miedo las grandes potencias sustituyan la agenda de la esperanza, obsesionándose únicamente con el tema de la seguridad". No queremos el terrorismo que sacrifica vidas humanas en forma cruenta, porque lo hemos llorado al menos durante dos décadas y tampoco ahora estamos libres de todo peligro. No queremos el terrorismo que amenaza al Norte, porque ese miedo también se traduce en mayores armamentos sofisticados, en otra forma de "guerra fría", que afecta las recesiones económicas del Norte y del Sur. Pero, también nos preguntamos por qué el miedo del Norte acaba con la esperanza del Sur. ¿Por qué el terrorismo del Norte es el problema número uno, y la esperanza del Sur es algo que siempre tiene que esperar?. No queremos terrorismos, en plural, porque los delegados del foro económico en Davos- Nueva York advirtieron que "la globalización de la ira se ha acelerado con el rápido crecimiento de las desigualdades sociales". Estamos en contra de la ira porque estamos en contra de las desigualdades, y la esperanza del Sur está doblemente amenazada por la ira y por las desigualdades. 